\title{
5-Oxo-ETE Induces Pulmonary Eosinophilia in an Integrin-Dependent Manner in Brown Norway Rats
}

\author{
Panagiota Stamatiou, ${ }^{\star}$ Qutayba Hamid, ${ }^{\star}$ Rame Taha, ${ }^{\star}$ Wengui Yu, ${ }^{\star}$ Thomas B. Issekutz, Joshua Rokach, ${ }^{\S}$ \\ Subhash P. Khanapure,,$^{\S}$ and William S. Powell* \\ *Meakins-Christie Laboratories, Department of Medicine, McGill University, Montreal, Quebec, Canada, H2X 2P2; ${ }^{\ddagger}$ Department of \\ Pediatrics, Dalhousie University, Halifax, Nova Scotia, Canada B3J 3G9; and the ${ }^{\S}$ Claude Pepper Institute and Department of Chemistry, \\ Florida Institute of Technology, Melbourne, Florida 32901-6988
}

\begin{abstract}
We have shown previously that the 5-lipoxygenase product 5-oxo-6,8,11,14-eicosatetraenoic acid (5-oxo-ETE) is a highly potent eosinophil chemoattractant in vitro. To determine whether this substance can induce pulmonary eosinophil infiltration in vivo, it was administered to Brown Norway rats by tracheal insufflation. Eosinophils were then counted in lung sections that had been immunostained with an antibody to eosinophil major basic protein. 5-Oxo-ETE induced a dramatic increase in the numbers of eosinophils $\left(\mathrm{ED}_{50}, 2.5\right.$ $\mu \mathrm{g})$ around the walls of the airways, which reached maximal levels (five times control levels) between 15 and $24 \mathrm{~h}$ after administration, and then declined. $\mathrm{LTB}_{4}$ also induced pulmonary eosinophil infiltration with a similar $\mathrm{ED}_{50}$ but appeared to be somewhat less effective. In contrast, $\mathrm{LTD}_{4}$ and $\mathrm{LTE}_{4}$ were inactive. 5-Oxo-ETE-induced eosinophilia was unaffected by the $\mathrm{LTB}_{4}$ and PAF antagonists LY255283 and WEB 2170, respectively. However, it was inhibited by $\sim 75 \%$ by monoclonal antibodies to CD49d (VLA-4) or CD11a (LFA-1) but was not significantly affected by an antibody to CD11b (Mac-1). In conclusion, 5-oxo-ETE induces pulmonary eosinophilia in Brown Norway rats, raising the possibility that it may be a physiological mediator of inflammation in asthma. (J. Clin. Invest. 1998. 102:2165-2172.) Key words: asthma • inflammation • eicosanoids • leukotrienes • cell adhesion molecules
\end{abstract}

\section{Introduction}

Infiltration of eosinophils into the lungs is a fundamental trait of allergic asthma and appears to be central to the pathogenesis of this disease (1). Eosinophils migrate from the circulation into the airway tissue by first attaching to the vascular endothelium, traversing the endothelium, and then migrating towards the site of inflammation. These processes are regulated by adhesion molecules on eosinophils and endothelial cells and by a variety of eosinophil chemoattractants. Eosinophils express several adhesion molecules that are important for their

Address correspondence to W.S. Powell, Meakins-Christie Laboratories, 3626 St. Urbain Street, Montreal, Quebec, Canada H2X 2 P2. Phone: 514-398-3864, ext. 094071; FAX: 514-398-7483; E-mail: Bill@ Meakins.LAN.McGill.ca

Received for publication 14 October 1997 and accepted in revised form 19 October 1998.

J. Clin. Invest.

(C) The American Society for Clinical Investigation, Inc. 0021-9738/98/12/2165/08 \$2.00

Volume 102, Number 12, December 1998, 2165-2172

http://www.jci.org interaction with endothelial cells, including the $\beta 1$ integrin CD49d (very late antigen-4 [VLA-4] $]^{1}$ ), which interacts with vascular cell adhesion molecule-1, and the $\beta 2$ integrins CD11a (LFA-1) and CD11b (Mac-1), which interact with intercellular adhesion molecules (2).

Eosinophils respond to a variety of $\mathrm{CC}$ chemokines including eotaxin (3), eotaxin-2 (4), RANTES (regulated upon activation, normal $\mathrm{T}$ cell expressed and secreted) (5), MIP- $1 \alpha$ (macrophage inflammatory protein-1 $\alpha$ ) (6), MCP-3 (monocyte chemotactic protein-3) (7), and MCP-4 $(8,9)$. Of these, only the eotaxins are specific for eosinophils, since they interact with only one $\mathrm{CC}$ chemokine receptor (CCR-3), which is found exclusively on eosinophils (10). Certain lipid mediators also have chemoattractant effects on eosinophils. Platelet-activating factor (PAF) has long been known to be a potent eosinophil agonist and has been implicated in the infiltration of these cells in asthma (11). The 5-lipoxygenase product leukotriene $\mathrm{B}_{4}\left(\mathrm{LTB}_{4}\right)$ is a potent chemoattractant for guinea pig (12-14) and rat (12) eosinophils but is not very active on human eosinophils in vitro (15). Another arachidonic acid metabolite, 8S,15S-dihydroxy-5,9,11,13-eicosatetraenoic acid (8S,15SdiHETE), also induces migration of guinea pig eosinophils, but it is considerably less potent than $\mathrm{LTB}_{4}(13)$.

We recently reported a novel pathway which gives rise to 5-oxo-eicosanoids (16). These substances are formed by the highly specific enzyme 5S-hydroxyeicosanoid dehydrogenase, which is found in neutrophils (16), eosinophils (15), monocytes (17), and lymphocytes (17). The preferred substrate for this pathway, 5S-hydroxy-6,8,11,14-eicosatetraenoic acid (5-HETE) is converted to its 5-oxo metabolite, 5-oxo-ETE. 5-Oxo-ETE is a chemoattractant for human neutrophils (18) and stimulates a variety of other responses in these cells (19-22). Although it affects a broad spectrum of neutrophil activities and appears to act via a specific receptor, 5-oxo-ETE is considerably less potent than $\mathrm{LTB}_{4}$ in inducing calcium mobilization (18), surface expression of CD11b (19), actin polymerization (19), degranulation (21), adherence (19), and chemotaxis (18).

In contrast to neutrophils, 5-oxo-ETE is much more active than $\mathrm{LTB}_{4}$ as an eosinophil chemoattractant $(15,23)$. It is also approximately two to three times more active than PAF in stimulating chemotaxis in these cells and appears to act synergistically with the latter compound (15). The related compound, 5-oxo-15-hydroxy-ETE, which is formed from 5,15diHETE by the same pathway (16), is also a potent eosinophil chemoattractant $(24,15)$. 5-Oxo-ETE also stimulates calcium

1. Abbreviations used in this paper: 5-HETE, 5S-hydroxy-6,8,11,14eicosatetraenoic acid; BN, Brown Norway; $\mathrm{LTB}_{4}$, 5-lipoxygenase product leukotriene $\mathrm{B}_{4}$; MBP, major basic protein; $\mathrm{MCP}$, monocyte chemotactic protein; MIP, macrophage inflammatory protein; PAF, platelet-activating factor; RANTES, regulated upon activation, normal $\mathrm{T}$ cell expressed and secreted; VLA-4, very late antigen-4. 
mobilization $(25,26)$, degranulation (23), superoxide formation (27), actin polymerization $(26,27)$, CD11b expression (26), and L-selectin shedding (26) in these cells. In general, it appears to be considerably more potent in stimulating eosinophils than neutrophils (23). In view of its potent in vitro effects on eosinophils, it was important to determine whether 5-oxoETE is also active in vivo. To address this question, we examined the effects of 5-oxo-ETE, administered intratracheally, on eosinophil infiltration into the lungs of Brown Norway (BN) rats. We found that 5-oxo-ETE is a potent eosinophil chemoattractant in vivo and that its effects can be blocked by antibodies to the eosinophil integrins CD11b and CD49d (i.e., VLA-4).

\section{Methods}

Chemicals. 5-Oxo-ETE was prepared by total chemical synthesis (28). $\mathrm{LTB}_{4}$ was synthesized by incubation of arachidonic acid $(\mathrm{Nu}-$ chek Prep. Inc., Elysian, MN) with porcine neutrophils in the presence of 5,8,11,14-eicosatetraynoic acid and A23187 (Calbiochem, La Jolla, CA) as previously described. $\mathrm{LTD}_{4}$ and $\mathrm{LTE}_{4}$ were obtained from the Cayman Chemical Co. (Ann Arbor, MI). Xylazine and sodium pentobarbital were purchased from Chemagro Limited (Etobicoke, Ontario, Canada) and MTC Pharmaceuticals (Cambridge, Ontario, Canada), respectively. The $\mathrm{LTB}_{4}$ and PAF antagonists LY255283 and WEB 2170, respectively, were kindly provided by Eli Lilly, (Indianapolis, IN), and Boehringer Ingelheim Pharmaceuticals, Inc. (Ridgefield, CT), respectively.

Antibodies. Mouse anti-rat monoclonal antibodies to CD49d (TA-2; $\mathrm{IgG}_{1}$ ) (29), CD11a (TA-3; $\mathrm{IgG}_{1}$ ) (30), and CD11b (OX-42;
$\mathrm{IgG}_{2 \mathrm{a}}$ ) (30) were prepared by immunizing BALB/c mice with leukocytes from $\mathrm{AO}$ rats and characterized as previously described. An irrelevant monoclonal antibody against pertussis toxin $\left(3 \mathrm{~h} 11-\mathrm{B} 9 ; \mathrm{IgG}_{1}\right)$ (31) was used as a control. A mouse monoclonal antibody to major basic protein (MBP) that has previously been shown to detect rat eosinophils (32) was a kind gift from Dr. R. Moqbel, University of Alberta, Edmonton, Canada.

Animals and in vivo procedures. Experiments were performed on highly inbred ( $>58$ generations) male BN rats (6- 8 wk old; $180-220 \mathrm{~g}$ RijHsd substrain), obtained from Harlan Sprague Dawley (Indianapolis, IN). Rats were anesthetized with xylazine $(7 \mathrm{mg} / \mathrm{kg})$ and pentobarbital $(50 \mathrm{mg} / \mathrm{kg})$ intraperitoneally. Endotracheal intubation was performed with a 6-cm length of polyethylene tubing (PE-240). Agonists in $100 \mu \mathrm{l}$ of saline containing $0.5 \%$ ethanol were administered by insufflation using a 1-ml syringe containing the agonist and $1 \mathrm{ml}$ of air to force the agonist into the lungs. Alternatively, agonists in $100 \mu \mathrm{l}$ of saline containing $0.5 \%$ ethanol were instilled directly into the trachea without the use of air. Control animals received vehicle alone. After administration of the agonist, the animals awakened spontaneously and were extubated. At various time intervals, the animals were anesthetized, and the lungs were removed for immunocytochemistry as described below.

In some cases, rats were treated with antagonists to either $\mathrm{LTB}_{4}$ (LY255283) or PAF (WEB 2170) or vehicle (0.2\% carboxymethylcellulose in water [wt/vol]; Sigma Chemical Co., St. Louis, MO), administered by gavage $1 \mathrm{~h}$ before and $7 \mathrm{~h}$ after, agonist insufflation. Alternatively, rats were pretreated by intravenous injection of either anti-integrin or control monoclonal antibodies $(1.4 \mathrm{mg}$ in $0.5 \mathrm{ml}$ sterile saline) $30 \mathrm{~min}$ before agonist instillation. These amounts of antibodies have been shown previously to maximally block leukocyte migration in vivo and provide plasma levels that are several times higher than required to saturate integrins on blood leukocytes (29-31).

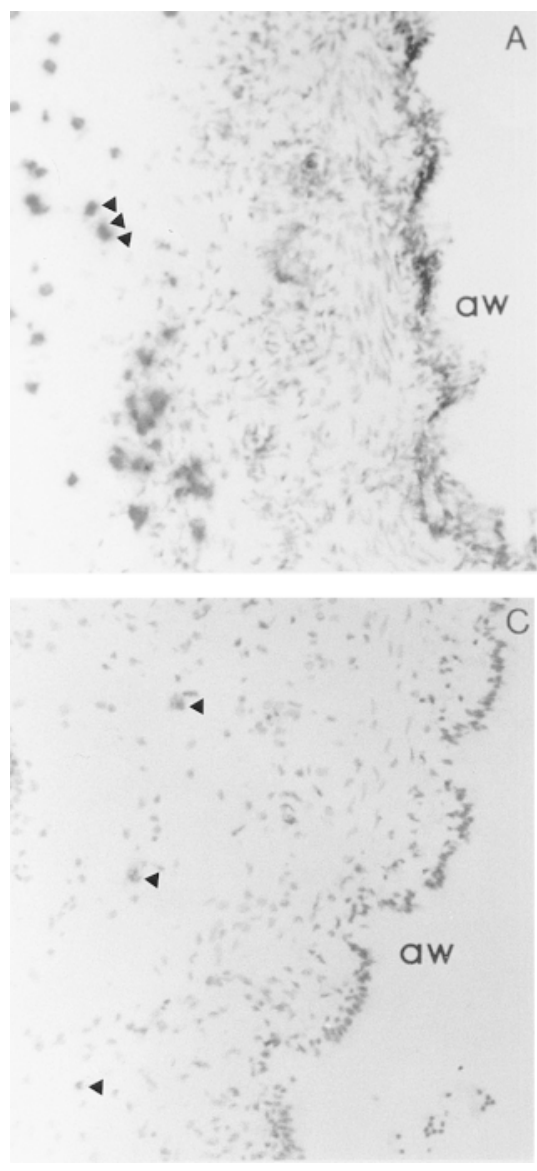

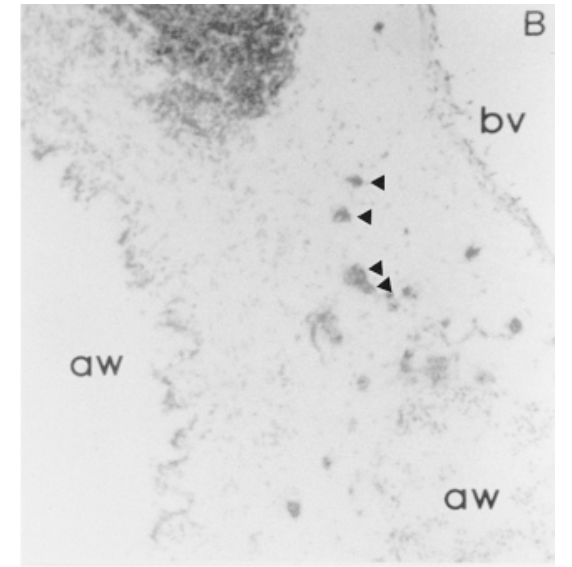

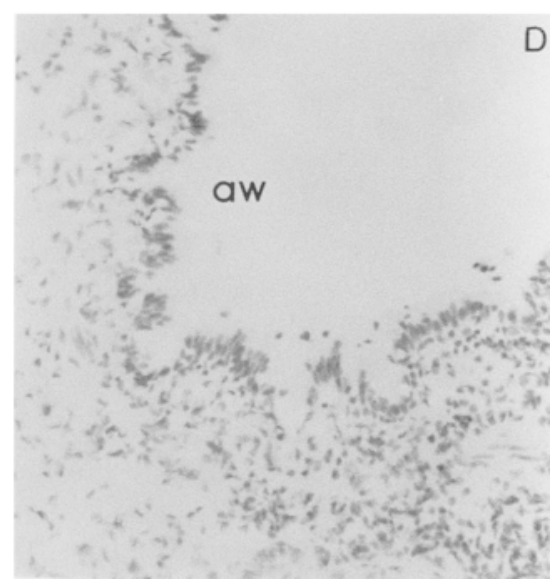

Figure 1. Immunocytochemical staining of lung sections (cryostat) for MBP by using the APAAP method. The location of airways (aw) and blood vessels $(b v)$ are indicated. $(A)$ An MBP-immunostained section from an animal that received 5-oxo-ETE $(5 \mu \mathrm{g}) 15 \mathrm{~h}$ before removal of the lungs $(\times 400) .(B)$ A lower power $(\times 200)$ view of an MBP-immunostained lung section from an animal that received $5 \mu \mathrm{g}$ of 5-oxo-ETE $15 \mathrm{~h}$ before removal of the lungs. $(C)$ A section immunostained for MBP from the lungs of an animal that received saline $15 \mathrm{~h}$ before removal of the lungs $(\times 400)$. $(D)$ Negative control in which a lung section from a rat treated with 5-oxo-ETE for $15 \mathrm{~h}$ was processed in a manner identical to the sections shown in $A-C$, except that PBS was substituted for the monoclonal antibody to MBP $(\times 400)$. MBP-positive cells were originally observed as red-stained cells, but in the figure they appear as dark cells as indicated by the arrowheads. Many such cells (not all of which are indicated) were observed in $A$ and $B$, whereas only the three cells indicated were positive in $C$. No positive cells were observed in $D$. 
Histology. After induction of anesthesia, rats were exsanguinated via the abdominal aorta. The lobes of the lungs were dissected around the hilum $(0.5 \times 1 \mathrm{~cm})$, immediately placed in phosphate-buffered saline and frozen within $30 \mathrm{~min}$. The tissue was then placed in OCT embedding medium and snap-frozen in isopentane precooled in liquid nitrogen and stored at $-80^{\circ} \mathrm{C}$. Sections of $6 \mu \mathrm{m}$ were cut in a cryostat, and three consecutive sections were placed on microscope slides. They were air-dried for $1 \mathrm{~h}$ and fixed in acetone/methanol (1:1) for 5 min and further air-dried for $1 \mathrm{~h}$. Slides were then wrapped back-toback in pairs in aluminum foil and stored at $-20^{\circ} \mathrm{C}$ before immunostaining.

Immunocytochemistry. Slides were allowed to defrost and then stained with a monoclonal antibody to MBP by using the alkaline phosphate-antialkaline phosphate (APAAP) method as previously described (33). To prevent nonspecific binding of the second and third antibodies, the sections were treated with $20 \%$ normal rat serum. Slides were coded and read in a blind fashion at $200 \times$ magnification. The numbers of positively stained cells were counted in the walls of the airways identified in a zone $115-\mu \mathrm{m}$ deep (as defined by a squared eyepiece graticule) along the length of the epithelial basement membrane. A calibrated computerized graphics tablet (IBM, White Plains, NY) was used to determine the length of the basement membrane. Cell counts are expressed as the mean numbers of immunoreactive cells per unit length $(1 \mathrm{~mm})$ of basement membrane of the airway.

Data analysis. One-way ANOVA using Dunnett's test as a multiple comparison method was used to determine whether there were statistically significant differences among groups of animals. For comparison of two groups, Student's $t$ test was used using the Bonferroni correction. All data are presented as means \pm SE $(n=5$, unless indicated otherwise). Differences were considered to be statistically significant for $P$ values of $<0.05$.

\section{Results}

5-Oxo-ETE is a strong inducer of pulmonary eosinophilia. $\mathrm{BN}$ rats were treated with either vehicle or 5-oxo-ETE $(5 \mu \mathrm{g})$, administered by tracheal insufflation. The lungs were removed after $15 \mathrm{~h}$, and sections were immunostained for MBP. 5-OxoETE induced a dramatic increase in the numbers of eosinophils detected in the lung as illustrated by Fig. 1, $A$ and $B$. The MBPpositive cells were found principally around the airways among other inflammatory cells. There were also occasional eosinophils around blood vessels and in the parenchyma (Fig. $1 B$ ). Lung sections from rats treated with vehicle instead of 5-oxoETE contained much smaller numbers of MBP-positive cells (Fig. $1 C$ ). Fig. $1 D$ shows a negative control in which lung sections from 5-oxo-ETE-treated rats were processed identically, except that the monoclonal antibody to MBP was omitted.

5-Oxo-ETE induces eosinophil infiltration in a time-dependent manner. $\mathrm{BN}$ rats (five animals per group) were treated with either vehicle or 5-oxo-ETE $(5 \mu \mathrm{g})$, administered by tracheal insufflation. The lungs were removed after various times $(6,15,24$, and $36 \mathrm{~h})$, and eosinophils were counted in sections immunostained for MBP. The effect of 5-oxo-ETE on eosinophil infiltration was obvious after $6 \mathrm{~h}$, the first time point chosen, at which time the numbers of eosinophils in the lungs of the 5-oxo-ETE-treated rats were approximately three times higher than in the controls $(P<0.05)$ (Fig. 2). This effect was maximal between $15 \mathrm{~h}(P<0.005)$ and $24 \mathrm{~h}(P<0.01)$, with the numbers of eosinophils increasing to approximately five times control values, and declining thereafter to approximately three times control values by $36 \mathrm{~h}(P<0.05)$. Subsequent experiments were therefore performed on rats 15 or $24 \mathrm{~h}$ after treatment with 5-oxo-ETE.

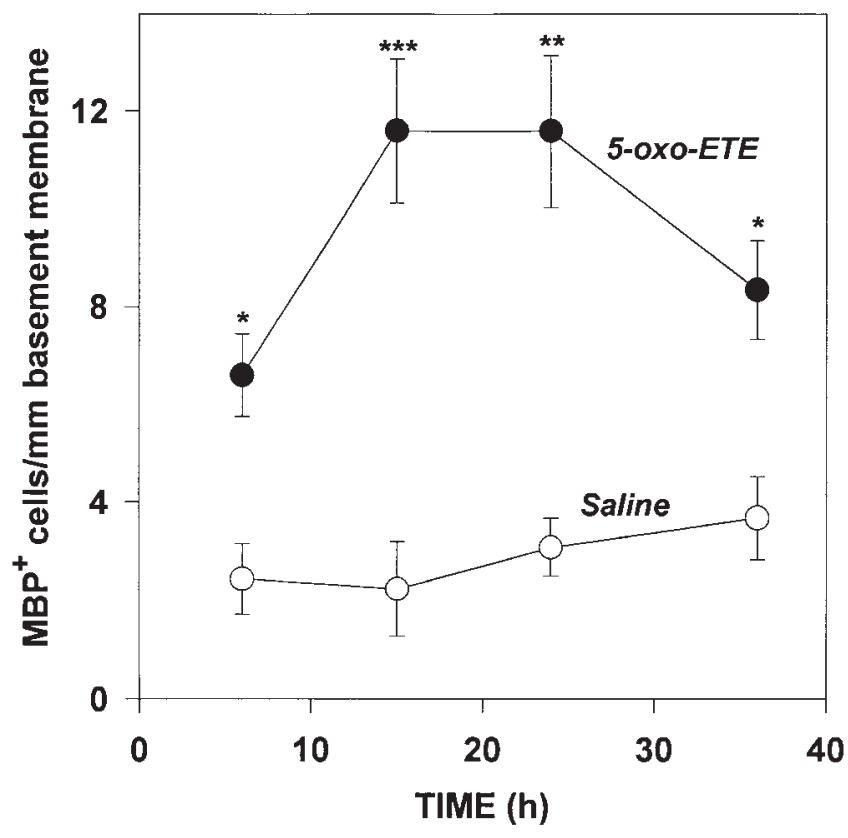

Figure 2. Time course for 5-oxo-ETE-induced eosinophil recruitment. BN rats were insufflated with 5-oxo-ETE $(5 \mu \mathrm{g} ; n=5)$ or vehicle $(100 \mu 10.5 \%$ ethanol in saline; $n=8)$. The lungs were removed 6 , 15,24 , or $36 \mathrm{~h}$ later and stained for eosinophils by using an antibody to MBP. The results are expressed as the numbers of positive cells per millimeter of basement membrane of the airway and are means \pm SE $(n=5)$. Differences between treated and control rats at different time points were evaluated using Student's $t$ test followed by a Bonferroni correction. $* P<0.05 ; * * P<0.01 ; * * * P<0.005$.

Comparison of effects of 5-oxo-ETE to those of other eicosanoids. The effects of 5-oxo-ETE were compared with those of various leukotrienes, including $\mathrm{LTB}_{4}, \mathrm{LTD}_{4}$, and $\mathrm{LTE}_{4}$. Rats $(n=5)$ were treated by administration of either vehicle or agonist $(5 \mu \mathrm{g})$ by tracheal instillation. After $24 \mathrm{~h}$, the lungs were removed, and sections were stained for MBP. Of the eicosanoids tested, only 5-oxo-ETE $(P<0.01)$ and $\mathrm{LTB}_{4}$ $(P<0.05)$ induced pulmonary eosinophil infiltration, with the numbers of eosinophils in lung sections being $\sim 3.5$ and 3 times, respectively, higher than in lung sections from control animals (Fig. 3). In contrast, eosinophil numbers in lungs from rats treated with $\mathrm{LTD}_{4}$ and $\mathrm{LTE}_{4}$ were the same as in control lungs.

Effects of $\mathrm{LTB}_{4}$ and PAF antagonists on 5-oxo-ETEinduced eosinophil infiltration. To determine whether the effects of 5-oxo-ETE on pulmonary eosinophilia could be mediated by either $\mathrm{LTB}_{4}$ or PAF, rats were treated with antagonists of these substances. 5-Oxo-ETE, $\mathrm{LTB}_{4}$, and PAF all strongly stimulated the accumulation of eosinophils in $\mathrm{BN}$ rat lungs $(P<0.0005$ compared with rats treated with vehicle alone $)$ (Fig. 4). LY255283 (20 mg/kg), an $\mathrm{LTB}_{4}$ antagonist that has been shown to be active in $\mathrm{BN}$ rats (12), inhibited the response to $\mathrm{LTB}_{4}$ by $72 \%(P<0.005)$ but had no effect on the response to 5-oxo-ETE. Similarly, WEB $2170(30 \mathrm{mg} / \mathrm{kg})$, a potent in vivo PAF antagonist $(34,35)$, strongly inhibited the response to PAF by $78 \%(P<0.0001)$ but did not significantly affect the response to 5-oxo-ETE.

Dose response for the effects of 5-oxo-ETE and $\mathrm{LTB}_{4}$ on eosinophil infiltration. BN rats were treated with either vehi- 


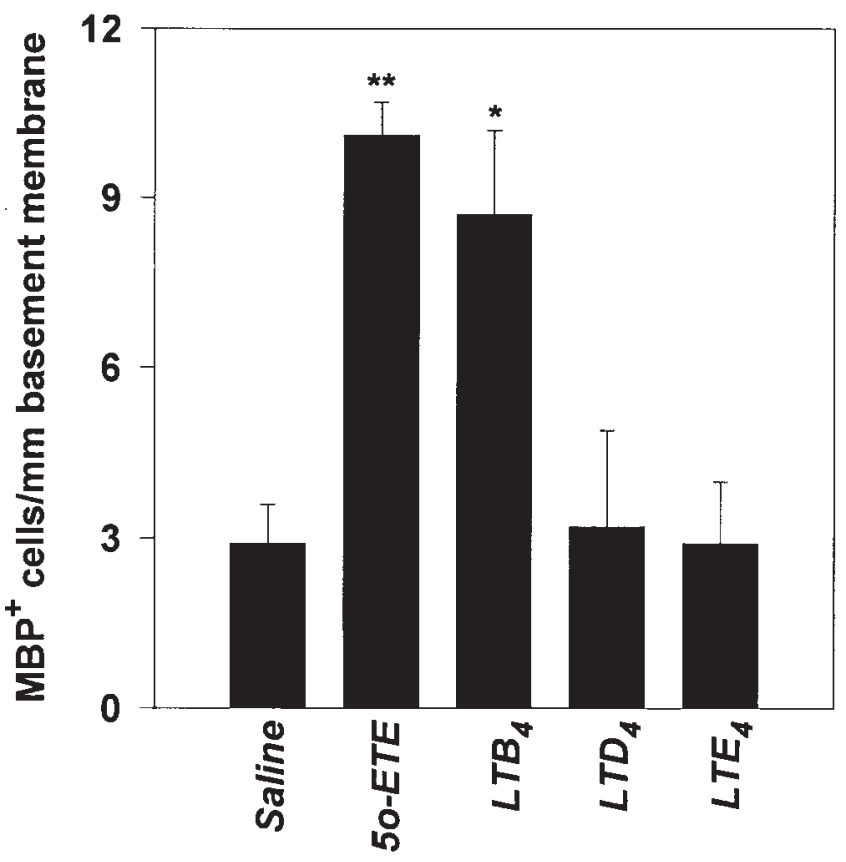

Figure 3. Comparison of the effects of 5-oxo-ETE to those of leukotrienes on pulmonary eosinophil recruitment. Various eicosanoids (5 $\mu \mathrm{g})$ or vehicle (100 $\mu \mathrm{l} 0.5 \%$ ethanol in saline) was administered to BN rats by tracheal instillation, and the lungs were removed $24 \mathrm{~h}$ later, and sections were stained for eosinophils by using an antibody to MBP. The results are expressed as the numbers of positive cells per millimeter of airway basement membrane and are means \pm SE $(n=$ $5)$. Differences among groups were evaluated by one-way ANOVA with Dunnett's test as a multiple comparison method. $* P<0.05$; $* * P<0.01$.

cle $(n=8)$ or various amounts of 5-oxo-ETE or $\operatorname{LTB}_{4}(2,5$, and $10 \mu \mathrm{g} ; n=5$ ), administered by tracheal insufflation. After $15 \mathrm{~h}$, the lungs were removed, and the numbers of eosinophils were counted in lung sections after immunostaining for MBP. Both agonists induced a dose-dependent increase in pulmonary eosinophils, which was maximal at a dose of $5 \mu \mathrm{g}$ in each case (Fig. 5). The dose-response curves for the two eicosanoids were similar to one another, except that the maximal response to 5-oxo-ETE was nearly twice that to $\operatorname{LTB}_{4}(P<0.05)$. The smallest amounts $(2 \mu \mathrm{g})$ of 5-oxo-ETE $(P<0.01)$ and $\mathrm{LTB}_{4}$ $(P<0.05)$ used increased pulmonary eosinophil numbers to $\sim 2.6$ and 2.3 times, respectively, the number in lungs from control rats. This increased to $\sim 5.5$ times (5-oxo-ETE) and 3.5 times $\left(\mathrm{LTB}_{4}\right)$ the control levels with the highest doses used $(P<0.005)$.

Effects of anti-integrin antibodies on 5-oxo-ETE-induced eosinophil infiltration. To determine whether the 5-oxo-ETEinduced eosinophilia was dependent on eosinophil integrins, rats $(n=5)$ were pretreated with monoclonal antibodies to CD11a, CD11b, and CD49d 30 min before intratracheal insufflation with of 5-oxo-ETE $(5 \mu \mathrm{g})$. The amounts of antibodies used have been shown previously to be sufficient to saturate integrins on blood leukocytes (29-31). The lungs were removed $15 \mathrm{~h}$ later and sections stained for MBP. In agreement with the results discussed above, administration of 5-oxo-ETE to vehicle-pretreated rats resulted in a nearly eightfold increase in the numbers of lung eosinophils around the airways when compared with control, vehicle-treated animals. $(P<$

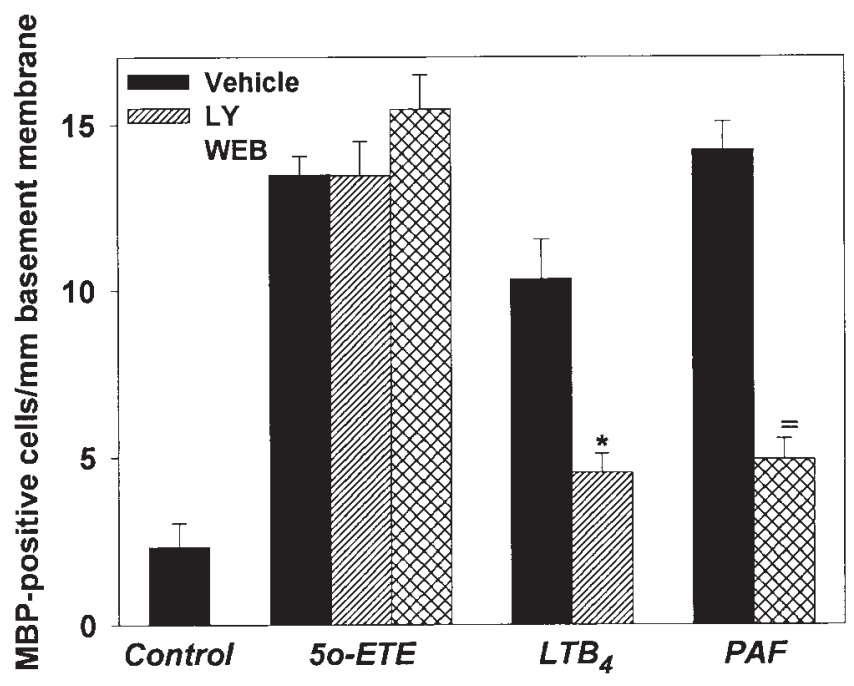

Figure 4. Effects of $\mathrm{LTB}_{4}$ and PAF antagonists on 5-oxo-ETEinduced pulmonary eosinophilia. BN rats were treated by gavage with either vehicle $(0.2 \%$ carboxymethylcellulose in water $(\mathrm{wt} / \mathrm{vol})$; solid bars), the $\mathrm{LTB}_{4}$ antagonist LY255283 (20 mg/kg; hatched bars), or the PAF antagonist WEB $2170(30 \mathrm{mg} / \mathrm{kg}$; cross-hatched bars $)$. The animals were anesthetized, intubated, and then treated with either vehicle or $5 \mu \mathrm{g}$ of either $\mathrm{LTB}_{4}, \mathrm{PAF}$, or 5-oxo-ETE by tracheal insufflation $1 \mathrm{~h}$ after treatment with antagonists. $7 \mathrm{~h}$ after tracheal insufflation, vehicle or antagonists were again administered by gavage. After an additional $8 \mathrm{~h}$, the lungs were excised, and sections were stained for eosinophils by using an antibody to MBP. The results are expressed as the numbers of positive cells per millimeter of airway basement membrane and are means \pm SE $(n=5$ for all groups except "vehicle + PAF" $[n=7]$ and "WEB $2170+5$-oxo-ETE" $[n=8])$. $* P<0.005$ vs. $\mathrm{LTB}_{4}$ alone; ${ }^{*} P<0.0001$ vs. PAF alone.

0.005) (Fig. 6). Pretreatment of rats with the irrelevant control monoclonal antibody 3H11-B9 had little effect on 5-oxo-ETEinduced eosinophil infiltration. However, pretreatment of rats with a monoclonal antibody to CD49d inhibited the response to 5-Oxo-ETE by $70 \%(P<0.01)$ when compared with the response of animals pretreated with the irrelevant control antibody. Anti-CD11a had a similar effect, inhibiting the response to 5-Oxo-ETE by $77 \%,(P<0.005)$ whereas anti-CD11b had a smaller effect, reducing pulmonary eosinophils by only $30 \%$ (not significant). The combined effect of anti-CD11a and antiCD11b (80\% inhibition; $P<0.005)$ was similar to that of antiCD11a alone.

\section{Discussion}

It is clear that a variety of mediators displays chemoattractant properties for eosinophils and may be involved in the infiltration of these cells into the lung in asthma. Chemokines, notably eotaxin, are potent eosinophil chemoattractants and certainly are critical mediators in the accumulation of these cells in tissues. However, it would seem unlikely that a single mediator is responsible for this phenomenon and that several chemoattractant molecules act in concert, either in series or in parallel, in inducing the migration of eosinophils into tissues. For example, disruption of the eotaxin gene in mice (36) or administration of antibodies to eotaxin (37) only partially inhibited the recruitment of eosinophils into the airways after antigen challenge of sensitized mice. Partial inhibition of anti- 


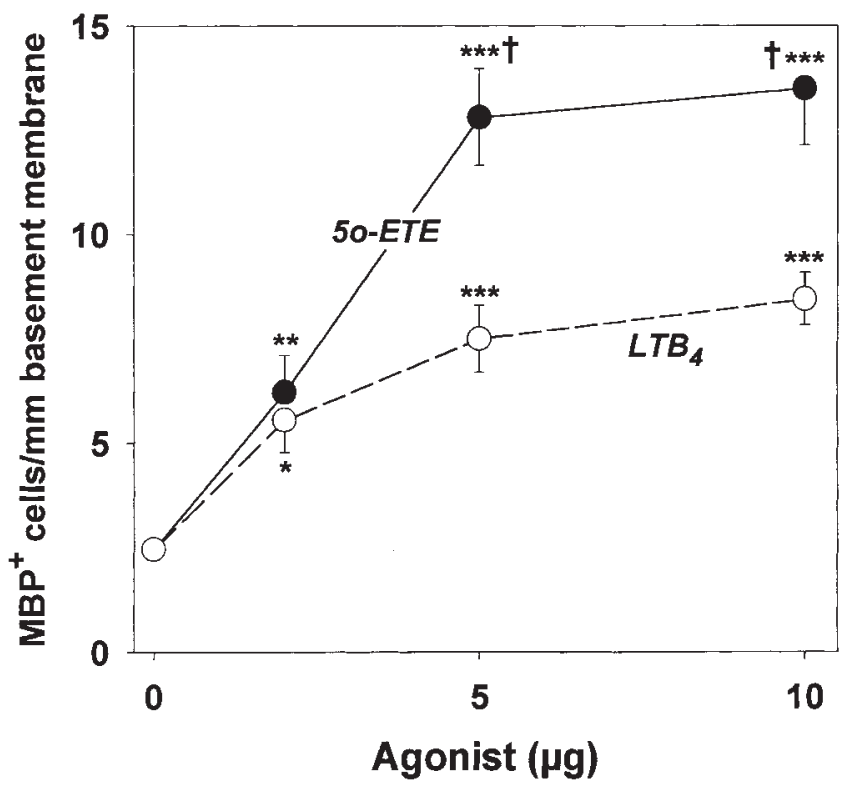

Figure 5. Dose response for the effects of 5-oxo-ETE and $\mathrm{LTB}_{4}$ on eosinophil infiltration. 5-Oxo-ETE, $\mathrm{LTB}_{4}(2,5$, or $10 \mu \mathrm{g})$, or vehicle (100 $\mu \mathrm{l}$ of $0.5 \%$ ethanol in saline) was administered to $\mathrm{BN}$ rats by tracheal insufflation. The lungs were removed $15 \mathrm{~h}$ later, and sections were stained for eosinophils by using an antibody to MBP. The results are expressed as the numbers of positive cells per millimeter of airway basement membrane and are means $\pm \operatorname{SE}(n=5)$. Differences between groups were evaluated using Student's $t$ test. $* P<0.05$; $* * P<0.01 ; * * * P<0.005$ when comparing a given dose of the test group with the vehicle-treated control. ${ }^{\dagger} P<0.05$ when comparing the groups treated with identical doses of 5-oxo-ETE and $\mathrm{LTB}_{4}$.

gen-induced pulmonary eosinophilia was also observed after treatment of mice with antibodies against either MIP- $1 \alpha$ or RANTES (38).

Lipid mediators also appear to be important physiological mediators of eosinophil migration in vivo and could act in se- ries or in parallel with chemokines. 5-Lipoxygenase inhibitors have been shown to inhibit the infiltration of these cells into the airways in humans $(39,40)$ as well as other species $(41,42)$, and this may contribute to the beneficial effects (43) of these agents in asthmatics. Moreover, antigen-induced eosinophilia was reduced dramatically in mice lacking the normal 5-lipoxygenase gene compared with control antigen-challenged mice (44). Antigen-induced pulmonary eosinophilia was blocked by the 5-lipoxygenase inhibitor PF 5901 but not by the $\mathrm{LTB}_{4}$ antagonist PF 10042 in guinea pigs (45). Sephadex-induced pulmonary eosinophilia was strongly inhibited in the $\mathrm{BN}$ rat by Zileuton, another 5-lipoxygenase inhibitor (46). Neither the $\mathrm{LTB}_{4}$ antagonist CGS-25019c nor the cys-LT $\mathrm{L}_{1}$ receptor antagonist MK-476 (Montelukast), except at high doses when it also inhibited the formation of leukotrienes, was capable of reproducing the effect of Zileuton on eosinophil infiltration (46). These results raise the possibility that a 5-lipoxygenase product other than $\mathrm{LTB}_{4}$ or the cys-LTs is involved in eosinophil recruitment in these animals. It is possible that 5-oxo-ETE could fulfill such a role. We (15) and others $(23,25)$ have shown that 5-Oxo-ETE is a potent chemoattractant for human eosinophils in vitro. However, it was not previously known whether this arachidonic acid metabolite is also active in vivo or indeed whether it is active on eosinophils from species other than humans. To answer this question, we chose the BN rat as an experimental model because it is an acceptable model of human asthma (47) and displays marked accumulation of eosinophils in the lungs in response to antigen challenge (12).

Our results clearly show that intratracheally administered 5-oxo-ETE induces the accumulation of eosinophils in the lungs of $\mathrm{BN}$ rats in a time- and dose-dependent manner. Between 15 and $24 \mathrm{~h}$ after treatment of rats with 5-oxo-ETE, the levels of eosinophils in the lungs were dramatically higher than in control, vehicle-treated animals. To the best of our knowledge, this is the first report that 5-oxo-ETE has biological effects in vivo. The effect of 5-oxo-ETE on eosinophil infiltration was quite reproducible, although there was some variability in the fold increase over control among the different exper-

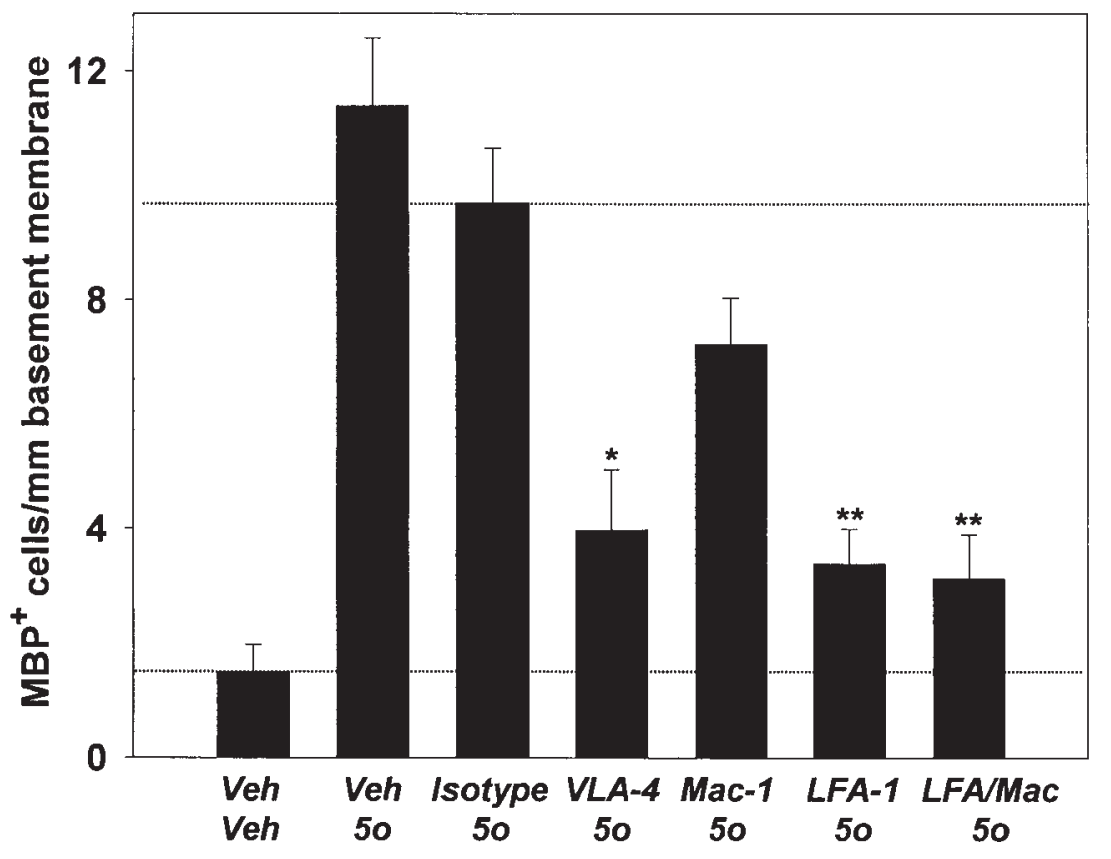

Figure 6. Effects of monoclonal antibodies to integrins on 5-oxo-ETE-induced eosinophil recruitment. BN rats were injected intravenously with either vehicle $(0.5 \mathrm{ml})$ or saturating amounts of antibodies to VLA-4, Mac-1, LFA-1, or a combination of LFA-1 and Mac-1. A control group of animals was pretreated with an irrelevant $\mathrm{IgG}_{1}$ antibody. After $30 \mathrm{~min}$, either 5-oxo-ETE $(5 \mu \mathrm{g})$ or vehicle ( $100 \mu \mathrm{l}$ of $0.5 \%$ ethanol in saline) was administered by intratracheal insufflation. The lungs were removed $24 \mathrm{~h}$ later, and sections were stained for eosinophils by using an antibody to MBP. The results are expressed as the numbers of positive cells per millimeter of airway basement membrane and are means \pm SE $(n=5)$. Differences among groups were evaluated by one-way ANOVA with Dunnett's test as a multiple comparison method. $* P<0.01 ; * * P<0.005$. 
iments. This was due in large part to variability in the mean numbers of eosinophils in control lungs in the different groups, which varied between 1.5 and 3.1 cells $/ \mathrm{mm}$ basement membrane, presumably due to biological variability among the different rats. In comparison, the mean numbers of eosinophils in the lungs of 5-oxo-ETE-treated animals varied between 10.1 and 13.2 among experiments.

Other 5-lipoxygenase products also have been reported to be active as eosinophil chemoattractants. Although $\mathrm{LTB}_{4}$ is not very effective in stimulating human eosinophil chemotaxis (15), it is a potent chemoattractant for guinea pig eosinophils, both in vitro $(13,14)$ and in vivo $(12)$ and also stimulates the accumulation of these cells after administration to $\mathrm{BN}$ rats by aerosol (12). Moreover, in contrast to the studies discussed above $(45,46)$, the $\mathrm{LTB}_{4}$ antagonist LY255283 was found to partially block antigen-induced pulmonary eosinophil accumulation in both rats and guinea pigs (12). Although this compound is a good inhibitor of the actions of $\operatorname{LTB}_{4}(48)$, we found that at higher concentrations it can also partially inhibit 5-oxoETE-induced responses (18). There is also evidence that cysLTs have chemotactic effects on human eosinophils in vitro (49), although we have found them to be far less active than 5-oxo-ETE in this respect (15). $\mathrm{LTE}_{4}$ has been reported to cause eosinophil infiltration into the airways of human asthmatics (50), whereas in vivo administration of $\mathrm{LTD}_{4}$ was shown to induce the accumulation of these cells in guinea pig conjunctiva (51). Furthermore, the cys- $\mathrm{LT}_{1}$ antagonist MK-571 partially inhibited antigen-induced eosinophil infiltration in guinea pig conjunctiva (51). It is not clear whether the effects of cys-LTs on eosinophil accumulation in the above studies were due to a direct action on eosinophils or whether these agents stimulated the release of other mediators such as PAF or 5-oxo-ETE. Cys-LTs are known to stimulate the release of eicosanoids (52) and PAF (53) from various tissues and cells, and it is thus quite possible that their in vivo chemotactic effects could be mediated by an indirect mechanism.

Although our previous studies suggest that 5-oxo-ETE stimulates human eosinophils directly and acts independently of other lipid mediators in vitro (26), we could not rule out the possibility that its action on in vivo eosinophil recruitment in the rat may be indirect. It would seem unlikely that 5-oxo-ETE acts via cys- $\mathrm{LT}_{1}$ receptors, since $\mathrm{LTD}_{4}$ and $\mathrm{LTE}_{4}$ did not appear to induce eosinophil infiltration in the present study (Fig. 3). The failure of $\mathrm{LTB}_{4}$ and PAF antagonists to block the response to 5-oxo-ETE, while strongly suppressing the responses mediated by activation of their target receptors (Fig. 4), would also seem to rule out the possibility that 5-oxo-ETE acts by stimulating receptors for these mediators in vivo.

Comparison of the effects of 5-oxo-ETE on eosinophil migration to those of other lipid mediators would suggest that it may be the most significant eosinophil chemoattractant among this class of substances. Our previous in vitro data (15) along with data from other laboratories (23) indicate that 5-oxo-ETE is much more active than any of the leukotrienes in stimulating chemotaxis of human eosinophils. Furthermore, the present study would suggest that it is much more effective than the cysLTs and perhaps somewhat more effective than $\mathrm{LTB}_{4}$ in inducing pulmonary eosinophilia in vivo in the $\mathrm{BN}$ rat. As discussed above, there is an abundance of data in the literature to support a role for 5-lipoxygenase products in eosinophil infiltration in vivo, suggesting that members of this family act along with eotaxin and other chemokines in regulating eosino- phil migration. There may also be some interactions between these two classes of eosinophil chemoattractants, since eotaxin and other chemokines have been shown to stimulate the release of eicosanoids from basophils (4).

Our findings that monoclonal antibodies to CD11a and CD49d strongly inhibit 5-oxo-ETE-induced pulmonary eosinophilia indicate that these integrins are required for this response. Furthermore, these results suggest that the response to 5-oxo-ETE is due to the entry of circulating eosinophils into the lung rather than to the maturation of progenitor cells already present within the lung. The importance of CD11a and CD49d is in agreement with previous findings showing that these integrins are required for allergen-induced infiltration of eosinophils into the lungs of sensitized $\mathrm{BN}$ rats $(54,55)$. In contrast, CD11b appears to play a relatively minor role in 5-oxoETE-induced eosinophil infiltration, in spite of the fact that we recently have found that this compound stimulates the surface expression of CD11b on both neutrophils (19) and eosinophils (26) in vitro. The modest effect of anti-CD11b on eosinophil recruitment is in accord with recent findings with neutrophils showing that migration of these cells into the peritoneal cavity is not impaired in CD11b-deficient mice (56). Thus, although CD11b may be important for certain aspects of neutrophil (56) and eosinophil activation and adherence, it does not appear to be a requirement for the infiltration of these cells into tissues.

As reviewed in the introduction, it is clear that 5-oxo-ETE is a potent activator of eosinophils in vitro. Moreover, this compound induces rapid changes in the expression of adhesion molecules on human eosinophils, including upregulation of CD11b and shedding of L-selectin (26). This would suggest that the in vivo effects of this substance reported in the present study are due to direct effects of 5-oxo-ETE on eosinophils. However, although increased numbers of eosinophils were apparent at the earliest time point investigated $(6 \mathrm{~h})$, the time required to reach the maximal response to 5-oxo-ETE was rather long (15 h). Therefore, we cannot rule out other mechanisms such as interactions with chemokines or cytokines such as GM-CSF, which has been shown to enhance eosinophil responses to 5-oxo-ETE (23).

In conclusion, 5-oxo-ETE is a potent activator of human eosinophils in vitro and induces their accumulation in the lungs of $\mathrm{BN}$ rats in vivo. These results raise the possibility that this compound may be an important physiological mediator of eosinophil infiltration in asthma and other diseases in which these cells are a distinctive feature. However, further studies using specific 5-oxo-ETE antagonists, as well as the measurement of 5-oxo-ETE in biological fluids such as bronchoalveolar lavage fluid clearly would be required to address this hypothesis. Unfortunately, 5-oxo-ETE antagonists are currently unavailable, but the development of a mass spectrometric assay for this substance will hopefully be attainable in the near future (28).

\section{Acknowledgments}

We would like to thank Sylvie Gravel for assistance with the preparation of $\mathrm{LTB}_{4}$, Rosa Pantano for assistance in the treatment of animals, and Dr. Heberto Ghezzo for help with the statistical analyses.

This work was supported by grants from the Respiratory Health Network of Centres of Excellence (WSP, QH, and TBI), the Medical Research Council of Canada (WSP), the National Institutes of Health 
(grant number DK-44730 to JR), the National Science Foundation (grant number CHE-90-13145 to JR for an AMX-360 NMR instrument), and the Costello Foundation.

\section{References}

1. Seminario, M.C., and G.J. Gleich. 1994. The role of eosinophils in the pathogenesis of asthma. Curr. Opin. Immunol. 6:860-864.

2. Wardlaw, A.J., G.M. Walsh, and F.A. Symon. 1996. Adhesion interactions involved in eosinophil migration through vascular endothelium. Ann. NY. Acad. Sci. 796:124-137.

3. Garcia-Zepeda, E.A., M.E. Rothenberg, R.T. Ownbey, J. Celestin, P. Leder, and A.D. Luster. 1996. Human eotaxin is a specific chemoattractant for eosinophil cells and provides a new mechanism to explain tissue eosinophilia. Nat. Med. 2:449-456.

4. Forssmann, U., M. Uguccioni, P. Loetscher, C.A. Dahinden, H. Langen, M. Thelen, and M. Baggiolini. 1997. Eotaxin-2, a novel CC chemokine that is selective for the chemokine receptor CCR3, and acts like eotaxin on human eosinophil and basophil leukocytes. J. Exp. Med. 185:2171-2176.

5. Kameyoshi, Y., A. Dorschner, A.I. Mallet, E. Christophers, and J.M. Schröder. 1992. Cytokine RANTES released by thrombin-stimulated platelets is a potent attractant for human eosinophils. J. Exp. Med. 176:587-592.

6. Rot, A., M. Krieger, T. Brunner, S.C. Bischoff, T.J. Schall, and C.A. Dahinden. 1992. RANTES and macrophage inflammatory protein 1 alpha induce the migration and activation of normal human eosinophil granulocytes. J. Exp. Med. 176:1489-1495.

7. Dahinden, C.A., T. Geiser, T. Brunner, V. von Tscharner, D. Caput, P. Ferrara, A. Minty, and M. Baggiolini. 1994. Monocyte chemotactic protein 3 is a most effective basophil- and eosinophil-activating chemokine. J. Exp. Med. 179:751-756.

8. Garcia-Zepeda, E.A., C. Combadiere, M.E. Rothenberg, M.N. Sarafi, F. Lavigne, Q. Hamid, P.M. Murphy, and A.D. Luster. 1996. Human monocyte chemoattractant protein (MCP)-4 is a novel CC chemokine with activities on monocytes, eosinophils, and basophils induced in allergic and nonallergic inflammation that signals through the CC chemokine receptors (CCR)-2 and -3 . J. Immunol. 157:5613-5626.

9. Stellato, C., P. Collins, P.D. Ponath, D. Soler, W. Newman, R.G. La, H. Li, J. White, L.M. Schwiebert, C. Bickel, et al. 1997. Production of the novel C-C chemokine MCP-4 by airway cells and comparison of its biological activity to other C-C chemokines. J. Clin. Invest. 99:926-936.

10. Daugherty, B.L., S.J. Siciliano, J.A. DeMartino, L. Malkowitz, A. Sirotina, and M.S. Springer. 1996. Cloning, expression, and characterization of the human eosinophil eotaxin receptor. J. Exp. Med. 183:2349-2354.

11. Barnes, P.J. 1989. New concepts in the pathogenesis of bronchial hyperresponsiveness and asthma. J. Allergy Clin. Immunol. 83:1013-1026.

12. Richards, I.M., F.F. Sun, B.M. Taylor, S.K. Shields, R.L. Griffin, J. Morris, D.G. Wishka, H.W. Smith, R.A. Johnson, and C.J. Dunn. 1991. Contribution of leukotriene $\mathrm{B}_{4}$ to airway inflammation and the effect of antagonists. Ann. NY. Acad. Sci. 629:274-287.

13. Sehmi, R., O. Cromwell, G.W. Taylor, and A.B. Kay. 1991. Identification of guinea pig eosinophil chemotactic factor of anaphylaxis as leukotriene $\mathrm{B}_{4}$ and 8(S),15(S)-dihydroxy-5,9,11,13(Z,E,Z,E)-eicosatetraenoic acid. J. Immunol. 147:2276-2283.

14. Maghni, K., A.J. de Brum-Fernandes, E. Foldes-Filep, M. Gaudry, P. Borgeat, and P. Sirois. 1991. Leukotriene $\mathrm{B}_{4}$ receptors on guinea pig alveolar eosinophils. J. Pharm. Exp. Ther. 258:784-789.

15. Powell, W.S., D. Chung, and S. Gravel. 1995. 5-Oxo-6,8,11,14-eicosatetraenoic acid is a potent stimulator of human eosinophil migration. J. Immunol. 154:4123-4132.

16. Powell, W.S., F. Gravelle, and S. Gravel. 1992. Metabolism of 5(S)hydroxy-6,8,11,14-eicosatetraenoic acid and other 5(S)-hydroxyeicosanoids by a specific dehydrogenase in human polymorphonuclear leukocytes. J. Biol. Chem. 267:19233-19241.

17. Zhang, Y., A. Styhler, and W.S. Powell. 1996. Synthesis of 5-oxo6,8,11,14-eicosatetraenoic acid by human monocytes and lymphocytes. J. Leukoc. Biol. 59:847-854.

18. Powell, W.S., S. Gravel, R.J. MacLeod, E. Mills, and M. Hashefi. 1993. Stimulation of human neutrophils by 5-oxo-6,8,11,14-eicosatetraenoic acid by a mechanism independent of the leukotriene $\mathrm{B}_{4}$ receptor. J. Biol. Chem. 268: 9280-9286.

19. Powell, W.S., S. Gravel, F. Halwani, C.S. Hii, Z.H. Huang, A.M. Tan, and A. Ferrante. 1997. Effects of 5-oxo-6,8,11,14-eicosatetraenoic acid on expression of CD11b, actin polymerization and adherence in human neutrophils. J. Immunol. 159:2952-2959.

20. Norgauer, J., M. Barbisch, W. Czech, J. Pareigis, U. Schwenk, and J.M. Schröder. 1996. Chemotactic 5-oxo-icosatetraenoic acids activate a unique pattern of neutrophil responses - analysis of phospholipid metabolism, intracellular $\mathrm{Ca}^{2+}$ transients, actin reorganization, superoxide-anion production and receptor up-regulation. Eur. J. Biochem. 236:1003-1009.

21. O'Flaherty, J.T., M. Kuroki, A.B. Nixon, J. Wijkander, E. Yee, S.L. Lee,
P.K. Smitherman, R.L. Wykle, and L.W. Daniel. 1996. 5-oxo-eicosanoids and hematopoietic cytokines cooperate in stimulating neutrophil function and the mitogen-activated protein kinase pathway. J. Biol. Chem. 271:17821-17828.

22. O'Flaherty, J.T., J.F. Cordes, S.L. Lee, M. Samuel, and M.J. Thomas. 1994. Chemical and biological characterization of oxo-eicosatetraenoic acids. Biochim. Biophys. Acta. 1201:505-515.

23. O'Flaherty, J.T., M. Kuroki, A.B. Nixon, J. Wijkander, E. Yee, S.L. Lee, P.K. Smitherman, R.L. Wykle, and L.W. Daniel. 1996. 5-Oxo-eicosatetraenoate is a broadly active, eosinophil-selective stimulus for human granulocytes. J. Immunol. 157:336-342.

24. Schwenk, U., E. Morita, R. Engel, and J.M. Schröder. 1992. Identification of 5-oxo-15-hydroxy-6,8,11,13-eicosatetraenoic acid as a novel and potent human eosinophil chemotactic eicosanoid. J. Biol. Chem. 267:12482-12488.

25. Schwenk, U., and J.M. Schröder. 1995. 5-Oxo-eicosanoids are potent eosinophil chemotactic factors-functional characterization and structural requirements. J. Biol. Chem. 270:15029-15036.

26. Powell, W.S., S. Gravel, and F. Halwani. 1998. Effects of 5-oxo6,8,11,14-eicosatetraenoic acid and other lipid mediators on the expression of adhesion molecules, actin polymerization, and calcium mobilization in human eosinophils. Am. J. Respir. Cell Mol. Biol. In press.

27. Czech, W., M. Barbisch, K. Tenscher, E. Schopf, J.M. Schröder, and J. Norgauer. 1997. Chemotactic 5-oxo-eicosatetraenoic acids induce oxygen radical production, $\mathrm{Ca}^{2+}$-mobilization, and actin reorganization in human eosinophils via a pertussis toxin-sensitive G-protein. J. Invest. Dermatol. 108:108-112.

28. Khanapure, S.P., X.X. Shi, W.S. Powell, and J. Rokach. 1998. Total synthesis of potent proinflammatory 5-oxo-ETE and its 6,7-dihydro biotransformation product. J. Org. Chem. 63:337-342.

29. Issekutz, T.B., and A. Wykretowicz. 1991. Effect of a new monoclonal antibody, TA-2, that inhibits lymphocyte adherence to cytokine stimulated endothelium in the rat. J. Immunol. 147:109-116.

30. Issekutz, A.C., and T.B. Issekutz. 1992. The contribution of LFA-1 (CD11a/CD18) and MAC-1 (CD11b/CD18) to the in vivo migration of polymorphonuclear leucocytes to inflammatory reactions in the rat. Immunology. 76:655-661.

31. Halperin, S.A., T.B. Issekutz, and A. Kasina. 1991. Modulation of Bordetella pertussis infection with monoclonal antibodies to pertussis toxin. J. Infect. Dis. 163:355-361.

32. Eidelman, D.H., E. Minshall, R.J. Dandurand, E. Schotman, Y.L. Song, Z. Yasruel, R. Moqbel, and Q. Hamid. 1996. Evidence for major basic protein immunoreactivity and interleukin 5 gene activation during the late phase response in explanted airways. Am. J. Respir. Cell Mol. Biol. 15:582-589.

33. Ying, S., S.R. Durham, J. Barkans, K. Masuyama, M. Jacobson, S. Rak, O. Lowhagen, R. Moqbel, A.B. Kay, and Q.A. Hamid. 1993. T cells are the principal source of interleukin-5 mRNA in allergen-induced rhinitis. Am. $J$. Respir. Cell Mol. Biol. 9:356-360.

34. Heuer, H.O., B. Keller, and K. Urich. 1991. Action of the racemate and the isomers of the platelet-activating factor antagonist bepafant (WEB 2170) after oral administration to guinea-pigs and rats. Naunyn Schmiedebergs Arch. Pharmacol. 343:546-550.

35. Heuer, H.O., J. Casals-Stenzel, G. Muacevic, and K.H. Weber. 1990. Pharmacologic activity of bepafant (WEB 2170), a new and selective hetrazepinoic antagonist of platelet activating factor. J. Pharmacol. Exp. Ther. 255:962968.

36. Rothenberg, M.E., J.A. MacLean, E. Pearlman, A.D. Luster, and P. Leder. 1997. Targeted disruption of the chemokine eotaxin partially reduces antigen-induced tissue eosinophilia. J. Exp. Med. 185:785-790.

37. Gonzalo, J.A., C.M. Lloyd, L. Kremer, E. Finger, C. Martinez, M.H. Siegelman, M. Cybulsky, and J.C. Gutierrezramos. 1996. Eosinophil recruitment to the lung in a murine model of allergic inflammation - the role of $\mathrm{T}$ cells, chemokines, and adhesion receptors. J. Clin. Invest. 98:2332-2345.

38. Lukacs, N.W., R.M. Strieter, K. Warmington, P. Lincoln, S.W. Chensue, and S.L. Kunkel. 1997. Differential recruitment of leukocyte populations and alteration of airway hyperreactivity by C-C family chemokines in allergic airway inflammation. J. Immunol. 158:4398-4404.

39. Kane, G.C., M. Pollice, C.J. Kim, J. Cohn, R.T. Dworski, J.J. Murray, J.R. Sheller, J.E. Fish, and S.P. Peters. 1996. A controlled trial of the effect of the 5-lipoxygenase inhibitor, zileuton, on lung inflammation produced by segmental antigen challenge in human beings. J. Allergy Clin. Immunol. 97:646654

40. Wenzel, S.E., J.B. Trudeau, D.A. Kaminsky, J. Cohn, R.J. Martin, and J.Y. Westcott. 1995. Effect of 5-lipoxygenase inhibition on bronchoconstriction and airway inflammation in nocturnal asthma. Am. J. Respir. Crit. Care Med. 152:897-905.

41. Henderson, W.R., Jr., D.B. Lewis, R.K. Albert, Y. Zhang, W.J. Lamm, G.K. Chiang, F. Jones, P. Eriksen, Y.T. Tien, M. Jonas, and E.Y. Chi. 1996. The importance of leukotrienes in airway inflammation in a mouse model of asthma. J. Exp. Med. 184:1483-1494.

42. Abraham, W.M., A. Ahmed, A. Cortes, M.W. Sielczak, W. Hinz, J. Bouska, C. Lanni, and R.L. Bell. 1992. The 5-lipoxygenase inhibitor zileuton blocks antigen-induced late airway responses, inflammation and airway hyperresponsiveness in allergic sheep. Eur. J. Pharmacol. 217:119-126.

43. Israel, E., J. Cohn, L. Dube, and J.M. Drazen. 1996. Effect of treatment 
with zileuton, a 5-lipoxygenase inhibitor, in patients with asthma. A randomized controlled trial. Zileuton Clinical Trial Group. JAMA. 275:931-936.

44. Irvin, C.G., Y.P. Tu, J.R. Sheller, and C.D. Funk. 1997. 5-lipoxygenase products are necessary for ovalbumin-induced airway responsiveness in mice. Am. J. Physiol. 272:L1053-L1058.

45. Seeds, E.A., S. Kilfeather, S. Okiji, T.S. Schoupe, D. Donigi-Gale, and C.P. Page. 1995. Role of lipoxygenase metabolites in platelet-activating factorand antigen-induced bronchial hyperresponsiveness and eosinophil infiltration. Eur. J. Pharmacol. 293:369-376.

46. Namovic, M.T., R.E. Walsh, C. Goodfellow, R.R. Harris, G.W. Carter, and R.L. Bell. 1996. Pharmacological modulation of eosinophil influx into the lungs of Brown Norway rats. Eur. J. Pharmacol. 315:81-88.

47. Eidelman, D.H., S. Bellofiore, and J.G. Martin. 1988. Late airway responses to antigen challenge in sensitized inbred rats. Am. Rev. Respir. Dis. 137: $1033-1037$.

48. Herron, D.K., T. Goodson, N.G. Bollinger, D. Swansonbean, I.G. Wright, G.S. Staten, A.R. Thompson, L.L. Froelich, and W.T. Jackson. 1992. Leukotriene- $\mathrm{B}_{4}$ receptor antagonists: the LY255283-series of hydroxyacetophenones. J. Med. Chem. 35:1818-1828.

49. Spada, C.S., A.L. Nieves, A.H. Krauss, and D.F. Woodward. 1994. Comparison of leukotriene $\mathrm{B}_{4}$ and $\mathrm{D}_{4}$ effects on human eosinophil and neutrophil motility in vitro. J. Leukoc. Biol. 55:183-191.

50. Laitinen, L.A., A. Laitinen, T. Haahtela, V. Vilkka, B.W. Spur, and
T.H. Lee. 1993. Leukotriene $\mathrm{E}_{4}$ and granulocytic infiltration into asthmatic airways. Lancet. 341:989-990.

51. Chan, C.C., K. McKee, P. Tagari, P. Chee, and A. Ford-Hutchinson. 1990. Eosinophil-eicosanoid interactions: inhibition of eosinophil chemotaxis in vivo by a $\mathrm{LTD}_{4}$-receptor antagonist. Eur. J. Pharmacol. 191:273-280.

52. Sirois, P., M. Chagnon, P. Borgeat, and P. Vallerand. 1985. Role of cyclooxygenase products in the lung action of leukotrienes $\mathrm{A}_{4}, \mathrm{~B}_{4}, \mathrm{C}_{4}, \mathrm{D}_{4}$ and $\mathrm{E}_{4}$. Pharmacology. 31:225-236.

53. McIntyre, T.M., G.A. Zimmerman, and S.M. Prescott. 1986. Leukotrienes $\mathrm{C}_{4}$ and $\mathrm{D}_{4}$ stimulate human endothelial cells to synthesize platelet-activating factor and bind neutrophils. Proc. Natl. Acad. Sci. USA. 83:2204-2208.

54. Richards, I.M., K.P. Kolbasa, C.A. Hatfield, G.E. Winterrowd, S.L. Vonderfecht, S.F. Fidler, R.L. Griffin, J.R. Brashler, R.F. Krzesicki, L.M. Sly, et al. 1996. Role of very late activation antigen-4 in the antigen-induced accumulation of eosinophils and lymphocytes in the lungs and airway lumen of sensitized Brown Norway rats. Am. J. Respir. Cell Mol. Biol. 15:172-183.

55. Laberge, S., H. Rabb, T.B. Issekutz, and J.G. Martin. 1995. Role of VLA-4 and LFA-1 in allergen-induced airway hyperresponsiveness and lung inflammation in the rat. Am. J. Respir. Crit. Care Med. 151:822-829.

56. Lu, H., C.W. Smith, J. Perrard, D. Bullard, L. Tang, S.B. Shappell, M.L. Entman, A.L. Beaudet, and C.M. Ballantyne. 1997. LFA-1 is sufficient in mediating neutrophil emigration in Mac-1-deficient mice. J. Clin. Invest. 99:13401350 . 